THE COUNSELING NEEDS OF OLDER PERSONS

\author{
Jane E. Myers \\ Director, National Project on Counseling older People \\ American Personnel and Guidance Association \\ Falls Church, Virginia \\ Larry C. Loesch \\ Associate Professor and Graduate Coordinator \\ Department of Counselor Education \\ University of Florida \\ Gainesville, Florida
}

Rapid and continuing increases in the numbers of older. persons (i.e., over age 60) in the U.S. have focused attention on their need for effective professional social services. This need is particularly evident within the counseling profession since the desire, indeed demand, for counseling services for older persons is experiencing a parallel increase. Unfortunately, however, the counseling profession has generally been ill-prepared to meet this increasing demand since most counseling techniques, aids, and programs have been designed for use with persons in younger age groups (Sinick, 1976). There is, therefore, currently a great need for the development of counseling service methods and aids that are specifically appropriate for use with older persons.

The effective delivery of counseling services is to a large extent contingent upon possession of valid information about the clientele to be served. Most often such information is garnered from research studies that attempt to assess and evaluate the characteristics of specific groups of people. Typically these studies simply involve administering some psychometric instrument to a small sample. Yet, even such rudimentary information about older persons is generally unavailable or lacking in substantive value. At least two reasons for this situation are obvious. First, most of the psychometric instruments available are inappropriate (in terms of format, reading level, normative data, etc.) for use with older persons (Sinick, 1976). Second, much of the available "characteristic" data on older persons are derived from studies with such smali samples that generalization is difficult, if not impossible. Clearly, there is a need for more and better information about older persons if counseling services for them are to be effective. 
The starting point for the provision of effective counseling services for older persons is detemination of their counseling needs. Such information would be useful not only for the provision of counseling services but also for counselor preparation and counseling research. Acquisition of this information in turn necessitates use of an assessment instrument. Accordingly, the purposes of this study were to develop a valid measure of the counseling needs of older persons and subsequently to intexpret and evaluate the data resulting from the administration of that measure.

\section{INSTRUMENT DEVELOPMENT}

Item Generation

Blake (1975), Buckley (1972), stevens (1973), and others have emphasized the importance of structuring a counseling program so as to meet the counseling needs of older persons as they themselves perceive those needs. In this regard, numerous needs of older persons have been identified from a variety of (noncounseling) needs assessment surveys (e.g., Harris \& Associates, 1975; State of Florida, 1975). These surveys have approached the needs assessment problem from diverse theoretical perspectives, and while they examine an extensive number of needs of older persons, theoretical consistency and coherency among those needs is lacking. Since a sound theoretical basis is generally essential for valid assessment (Anastasi, 1976), we found it necessary to develop a comprehensive theoretical framework.

We derived the conceptual basis for the counseling needs of older persons from a review of the pertinent literature and research. The attempt to synthesize and integrate that review resulted in our identifying four areas of major concern in the lives of older persons and delineating 27 potential basic needs within those areas. Figure 1 shows an outline of the concern areas and related needs. It should be noted that the list contains only those needs with which we believed counselors could, or should, be of assistance. For example, we included psychological needs relating to the aging process, whereas we excluded medical needs since counselors typically would not be qualified to attend to medical needs.

In order to relate these general needs to counseling needs, we found an operational definition of counseling to be necessary. In its most basic sense, counseling means talking with people about their concerns or problems. Thus, a counseling need was operationally defined as the expressed desire to talk with someone in regard to an area of concern. 


\section{FIGURE 1}

Topical outline of the Major Life Concerns Underlying the OPCNS Items

I. Personal Concerns

A. Psychological concerns

1. Death and dying

2. Mental health

3. Decision making

B. Physical concerns

1. Health

2. Acceptance of aging process

3. Acceptance of self as one who is aging

II. Social concerns

A. Psychosocial concerns

1. Relationships with spouse

2. Sexual needs

3. Relationships with chilaren/other relatives

4. Relationships with significant (nonfamily) others

B. Group affiliation concerns

1. Social isolation

2. Identification with peers

III. Activity concerns

A. Employment concerns

1. Employnent

2. Aajustment to retirement

B. Leisure concerns

1. Hobbies

2. Service activities

3. Group recreational activities

C. Skills utilization concerns

1. Vocational evaluation

2. Learning new skilis

IV. Environmental concerns

A. Environmental needs concerns

1. Housekeeping functions

2. Meals preparation

3. Shopping assistance

B. Resource management concerns

1. Income budgeting

2. Identifying service resource persons

c. Service obtainment concerns

1. Legal services

2. Transportation

3. Housing 
The outline shown in Figure 1 served as the basis for the development of a 27 item questionnaire entitled the older Persons Counseling Needs Survey (OPCNS), each item of which related to a different need. The specific items of the OPCNS are listed in Figure 2. A 4-point, Iikert-type response scale was chosen over a 5- or 7-point scale in order to avoid undecided or neutral responses. The responses were weighted (Strongly Agree $=4$, Agree $=3$, Disagree $=2$, strongly Disagree $=1$ ) such that a greater degree of agreement was indicative of a greater counseling need.

\section{Pilot Testing}

A pilot test of the original questionnaire evaluated face validity, format, readability, and initial item reliabilities. The questionnaire was first reviewed by 15 professionals in fields such as gerontology (3), counseling (3), assessment (2), and research (1), and by lay older persons (6). The reviews resulted in several minor changes in format. The questionnaire was then evaluated by a reading specialist. After several minor item revisions, each item was established as being at the fifth grade or lower reading level.

After these initial revisions, the questionnaire was administered to 107 older persons contacted through a local senior center. The questionnaire was subsequently readministered to them after a two-week interval for test-retest reliability purposes. OnIy one of the 27 test-retest reliability coefficients failed to reach significance at the .05 level. Consequently, 26 of the items were retained, and the other item was revised in wording but not in basic content. A subsequent reliability study using 32 older persons resulted in the item's reliability reaching significance at the .05 level.

\section{PROCEDURES}

\section{Participants}

The theoretical basis of the sampling procedure was a hypothetical continuum ranging from independence to dependence in envirommental situation. That is, the participants ranged from those who were essentially self-sufficient to those who were highly dependent on others for even their most basic needs. within this range and in order of decreasing self-sufficiency, the subsample groups, with their corresponding respondent numbers, were: American Association of Retired Persons and National Retired Teachers Association members $(n=139)$; senior citizen, retirement community, and church affiliated members $(n=190)$; persons employed under Title IX of the older Americans 
FIGURE 2

Iterns of the older Persons Counseling Needs Survey

1. I would like someone to help me find transportation when I need it.

2. I would like to learn how to budget my current income.

3. I would like help finding something to do in my spare time.

4. I would like help in dealing with my children or other relatives.

5. I would like regular visits from someone to discuss my concerns and activities.

6. I would like to talk to someone about help in doing shopping.

7. I would like to talk to someone about my mental health.

8. I would like to talk to someone about help in cooking meals.

9. I would like to have help learning how to make decisions.

10. I would like to learn how people change physically as they get older.

11. I would like to talk to someone about the feelings I have about myself as I get older.

12. I would like help in finding friends.

13. I would like to take some tests to find out what types of things I might be good at doing.

14. I would like to have someone help me meet with other people my age to talk about common concerns.

15. I would like to talk to someone about finding help with housekeeping chores.

16. I would like to talk to someone about my sexual feelings.

17. I would like to talk to someone about social services in my community.

18. I would like to talk to someone about getting used to being retired.

19. I would like to talk to someone about finding something to do to feel useful.

20. I would like to know how to find legal help.

21. I would like to talk to someone about finding better housing.

22. I would like to talk to someone about death and dying.

23. I would like help in finding a job.

24. I would like help in dealing with my marital situation.

25. I would like to talk to someone about available classes.

26. I would like someone to arrange for me to participate in

recreational activities with others my age.

27. I would like to talk to someone about my health situation. 
Act $(n=61)$; those congregating at meal and senior centers $(n=311)$; homebound older persons receiving delivered meals or homemaker services $(n=115)$; residents of adult congregate living facilities (ACLF) $(n=12)$; and nursing home residents $(n=22)$.

The major intent of the sampling procedure was to obtain a sample representative of older persons (i.e., over age 6o) both in the state of Floxida and in the united states as a whole. several mitigating factors, either methodologically desirable or practical, prohibited a truly random sample of that population. For example, in order for the intended statistical analyses to be valid, some demographic subgroups (e.g., ethnic minorities) had to be proportionately overrepresented. In addition, approval to solicit responses from greater numbers of nursing home residents was not obtained because of the study"s time constraints. The eventual sample totaled 850 older persons.

The major demographic characteristics of the sample are shown in Table 1. The most significant deviation from random sample selection occurs in the race category, where $31 \%$ of the sample are classified as ethnic minorities.

\section{Instrument Administrations}

The 27 item opcNs, along with a 12 item demographic questionnaire, was administered to 713 of the participants in various group settings. The remaining 137 (who were either homebound or in nursing homes) received individual administrations from research aides we trained. One group of 42 older persons at a congregate meal site completed the OPCNS a second time after a two-week interval for test-retest reliability purposes.

The review of the literature on the needs of older persons revealed that a variety of psychological instruments have been used to investigate the relationships among those needs and various psychological dimensions. Accordingly, to investigate further those relationships and to evaluate the concurrent validity of the OPCNS, five of these instruments were also administered to various subsample groups. These administrations to older persons were as follows: 65 also completed the Multiple Affect Adjective Checklist (MAACI) (Zuckerman \& Iubin, 1965); 62. also completed the Death Concern Scale (DCS) (Dickstein, 1972); 71 also completed the survey of Personal Values (SPV) (Gordon, 1967); 71 also completed the survey of Interpersonal Values (SIV) (Gordon, 1976); and 106 also completed the Life Satisfaction Index-z (LSIZ) (Adams, 1969). Thus, 375 of the 850 participants completed one other instrument in adaition to the OPCNS. Complete descriptions and technical specifications of these five additional instruments are too 
TABLE 1

Demographic Characteristics of the sample

Characteristic

n

8

Sex:

Male

277

32

Female

573

68

Race :

Caucasian

587

69

Ethnic Minority

263

31

Marital status:

Single

72

8

Married

336

Widowed/Divorced/Separated

442

Employment status:

Retixed

666

78

In Labor Market

Residence city size:

$$
\begin{gathered}
0-2,500 \\
2,500-50,00 \\
50,000-250,000 \\
\text { over } 250,000
\end{gathered}
$$

184

32

372

23

197

9

303

36

Annual Income:

$$
\begin{array}{r}
0-\$ 5,000 \\
\$ 5,000-\$ 10,000 \\
\$ 10,000-\$ 15,000 \\
\$ 15,000-\$ 25,000 \\
\text { over } \$ 25,000
\end{array}
$$

598

71

154

59

18

31

3.5

0.5

Education:

None or some grade school

229

completed grade school

131

135

some high school

Completed high school

127

15

Business/technical school

Some college

Completed 2 years college 
extensive to be included here, and interested readers should refer to the sources cited. The various subscales of these instruments, however, will be identified in later tables.

Data Analysis

The initial data analyses were computations of the normal summary statistics for a psychometric instrument. These computations yielded means, standard deviations, and test-retest coefficients (Pearson's $r$ ) for each of the 27 opCNS items. After completion of the subsequent factor analysis, these statistics were also computed for the opCNS total score.

The second step in the data analysis was a factor analysis of the OPCNS item responses from the total sample of 850 persons. The purpose of the factor analysis was to deternine if OPCNS subscale scores could, or should, be computed on the basis of the factor structure. The method of factor analysis used was principal-factoring with iteration. Since a hypothetical set of constructs that would underlie the counseling needs was not evident from the review of the literature, we could make no speculations concerning the relationships among any factors that merge. Accordingly, an oblique rotation was planned as part of the factor analysis.

The third type of data analysis was a series of one-way analyses of variance (ANOVA) to test for significant differences on the bases of sex, race, marital status, income, and educational level. One-way ANOVAs, as opposed to one or more factorial ANOVAs, were used because of the number of factors (i.e., demographic characteristics) being analyzed. This series of ANOVAs was planned for use with the OPCNS total score and any subscales that might have been developed. When any of the analyses of variance yielded a significant $F$ ratio for those variables with three or more levels, the Student-Newman-Keuls procedure was used to determine the patterns of significant differences among the means.

The last set of analyses was computation of the Pearson product-moment correlation coefficients between the OPCNS total score and each of the various subscales of the other instruments administered.

Each of the above statistical analyses were conducted using standard statistical package for the Social sciences (SPSS) (Nie, Hull, Jenkins, Steinbrenner, \& Brent, 1975) computer programs. An alpha level of .05 was used for all analyses. 
The oPCNS item response means and standard deviations are shown in Table 2. These older persons indicated the greatest counseling needs for Item 1, which dealt with txansportation assistance. They indicated the least counseling needs for item 24, which dealt with marital relationships, and item 16, which dealt with sexual feelings. Beyond these extremes, the most obvious aspect of Table 2 data is the relative lack of variation among the means. Similarly, the standard deviations indicate generally consistent variation among the responses to the vaxious items.

The reliability coefficients for the various oPCNS items are also shown in Table 2. Relative to the means and standard deviations, the reliability coefficients show much greater variation. The least reliable items were those dealing with familial relationships (4), finding friends (12), and sexual feelings (16). The most reliable items were those focusing on meeting other older persons (14), adjusting to the retirement (18), housing (21), and employment (23). It should be noted, however, that even in light of the variation, all reliability coefficients were statistically significant.

The initial-factor matrix of our factor analysis procedure yielded only one factor with an eigenvalue greater than one (i.e., Kaiser criterion). Inspection of this matrix, however, revealed that the eigenvalues of the second, third, and fourth factors were approximately equal, before a relatively large drop to the eigenvalue of the fifth factor. It has been suggested that such a situation might yield a stable factor structure under some circumstances (Guertin \& Bailey, 1970). Accordingly, the first four factors were subjected to oblique rotation (direct oblimin criterion). The results of this procedure revealed that the factor structure had "collapsed" in that the factors had very high intercorrelations. Thus the opCNS does appear to be a unidimensional (i.e., singular construct) instrument. Therefore, the opcNs total score was developed by suming the weights of the responses to the individual items. The factor loadings of the oPCNS items axe also shown in Table 2 .

The sumary tables for the series of one-way analyses of variance axe shown in Table 3.

The difference between the male and female orCNS total score means was not significant at the .05 level. Statistically significant differences, however, were found on the bases of race, income level, and educational level. The ethnic minority older persons in this sample had significantly greater 
counseling needs than did the white older persons. The multiple comparisons (Student-Newman-Keuls) revealed that, in regard to: income level, respondents in the lowest category had significantly greater counseling needs than respondents in the highest income category. Similarly, older persons in the lowest category had significantly greater counseling needs than older persons in the highest category.

The correlations among the opcNs total score and the subscales of the various other instruments administered are shown in Table 4 . The expressed counseling needs of these older persons clearly were not related to either their personal or intexpersonal values as measured by the SPV and SIV, respectively. Similarly, their counseling needs were unrelated to their concerns about death as measured by the DCS. Their counseling needs were, however, significantly and positively related to the two general psychological states of depression and hostility as measured by the MACL. Thus, as their counseling needs increased, so too did their depression and hostility, or vice versa. Finally, their counseling needs were significantly and inversely related to their general life satisfaction as measured by the LSIZ. Thus, as their life satisfaction increased, their counseling needs decreased, or vice versa.

\section{DISCUSSION}

The results of this study indicate that the counseling needs of older persons are singularly comprehensive in nature. That is, these older persons have a variety of counseling needs that are all at approximately the same need level. This conclusion is supported by both the general lack of variation among the various item means and standard deviations and the results of the factor analysis. Thus, the counseling needs of the oldex persons in this sample vary in terms of one general degree or level; not in terms of relative degrees among the various needs. This conclusion has several major implications for the counseling profession.

The most important implication is that counseling practitioners should take a holistic approach when working with older persons. It appears that an older person is likely to have at least several different counseling needs simultaneously, and counselors must be able and prepared to assist with all of these needs simultaneously. Such an approach is consistent with the concept of "life-style counseling," wherein a counselor helps a person with a whole way of living rather than just with specific others (e.9., Butler, 1977), and this study offers strong support for that suggestion. 
TAETIB 2

opchs Itom Means, St fndard Deviations, TestRetest kelibility coefficients and

Factor Loatings

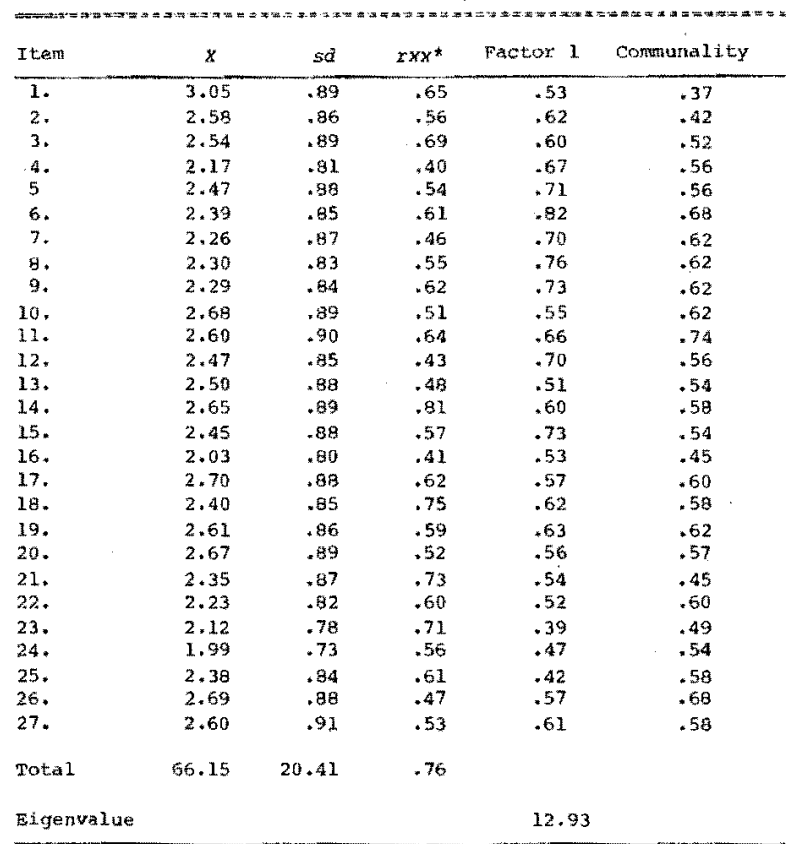

Ievel.

*all retiability coefficienta are significant at the .05

Thats 3

Sumana of opcoss Total 5 core Means and Dne-Way Analyoes of variance of the Means for various Demographic Chateteristios

\begin{tabular}{|c|c|c|c|c|c|c|}
\hline $\begin{array}{l}\text { Demographic } \\
\text { dategory }\end{array}$ & $\begin{array}{l}x \text { tas pex } \\
\text { Thble } 1\end{array}$ & source & SS & dit & MS & $F$ \\
\hline \multirow[t]{2}{*}{ Sex } & 65.73 & Between & .99 & 1 & .99 & \\
\hline & 65.90 & $\begin{array}{l}\text { Within } \\
\text { total }\end{array}$ & $\begin{array}{l}215,65 \mathrm{~B} * 31 \\
215,659,30\end{array}$ & $\begin{array}{l}848 \\
849\end{array}$ & 25.31 & .00 \\
\hline \multirow[t]{3}{*}{$\operatorname{Race}$} & 63.25 & Between & $12,1.7 .97$ & 1 & $12,117,97$ & \\
\hline & 71.42 & 样故in & $203,541.33$ & $\$ 48$ & 240,03 & \\
\hline & & Tota 1 & $215,659,30$ & 849 & & $54.49 *$ \\
\hline Maritat & 67.37 & Bectween & 587.33 & 4 & 146.83 & \\
\hline \multirow[t]{3}{*}{ Status } & 64.91 & Within & $215,071.97$ & 845 & 254.52 & \\
\hline & $\begin{array}{l}64 \cdot 66 \\
67 \cdot 01\end{array}$ & xotal & $215,659,30$ & 849 & & .58 \\
\hline & 66.12 & & & & & \\
\hline \multirow[t]{4}{*}{ Inoome } & 67.02 & Between & $3,959,55$ & 4 & 99.39 & \\
\hline & 64.24 & withen & $211,475,96$ & 243 & 250.86 & \\
\hline & 60.51 & Total & $215,465 . \$ 1$ & 947 & & $3.93^{*}$ \\
\hline & $\begin{array}{l}51.67 \\
54.50\end{array}$ & & & & & \\
\hline \multirow[t]{8}{*}{ Eacation } & 70.01 & Qetwaen & $3,027.73$ & 8 & $1,0,03.47$ & \\
\hline & 65.26 & thith & $207,515.20$ & 840 & 247.04 & \\
\hline & 65.74 & Total & 215.542 .93 & 344 & & $4.06 *$ \\
\hline & 64.20 & & & & & \\
\hline & 66.77 & & & & & \\
\hline & $\begin{array}{l}51.41 \\
65.51\end{array}$ & & & & & \\
\hline & 61.05 & & & & & \\
\hline & 69.44 & & & & $* \geqslant<$ & .05 \\
\hline
\end{tabular}


OPCNS Concurrent Validity Correlation Coeficients W OpCNs Total score

MAACL

$$
\begin{aligned}
& \text { Anxiety } \\
& \text { Depression } \\
& \text { Hostility }
\end{aligned}
$$

t:

.24

$.41 *$

$.46 *$

DCS

Total score

Contemplates Death

.08

Evaluates Death Negatively

.01

SPV

Practical mindedness

$-.17$

Achievement

.06

variety

$-.07$

Decisiveness

.06

oraerliness

.03

Goal orientation

SIV

Support

Conformity

Recognition

$-.14$

Independence

.07

Benevolence

$-.06$

Leadership

.03

.14

LSIZ

Total score

$-.29 *$

$\star p<.05$

As surely as generalizations are made, exceptions become evident. Accordingly, it seems imperative that counselors determine the need for a comprehensive (i.e., holistic) approach as early as possible in the counseling process since there are certainly older persons with only very specific counseling needs. Toward that end, the opCNS would seem to be an instrument with considerable utilitarian value. An inspection of the various item responses would provide a quick "picture" of the pattern of the older person's counseling needs. Likewise, the item response values and the total score would provide an indication of the strength (of immediacy) of the various needs. 
Even if an instrument such as the OPCNS was not used, however, at least a comprehensive, informal, verbal-needs assessment could be undertaken with the older client.

The results of this study also have implications for research on the needs, situations, or characteristics of older persons. Studies that are limited in scope and focus on only a very few factors have a high potential for error by ignoring pertinent, related information. Since the counseling needs of older persons are apparently so highly interrelated, it seems likely that other aspects of their lives are also highly interrelated. Consequently, research with older persons must be multifaceted so as to obtain valid results.

The last implication of this study concerns the professional preparation of counselors who will eventually work with older persons. It seems obvious that they must receive a highly diversified preparation so that they will be able to assist with the wide variety of counseling needs older persons may have. In addition, this preparation should sensitize counselors to the many possible individual variations in the counseling needs of older persons. Some of the data from this study suggest that there are needs differences that are characteristic of subgroups of older persons. For example, the results of this study suggest that ethnic minority older persons and those with extremely low income and educational levels may be expected to have strong counseling needs. These differences and trends, as well as those from other research, should be made available so that counselors may anticipate at least tentatively the counseling needs of particular types of clients. Combining this knowledge with other counseling skills will make counselors highly effective in their work with older persons.

The internal coherence of the results of this study may be somewhat surprising in light of the diverse counseling needs investigated. Yet upon closer scrutiny, we believe these results are consistent with the idea that it is difficult to affect one aspect of an older person's life without also affecting other aspects. This idea has been, and is, a basic tenet of most counseling approaches for working with older persons. Accordingly, it appears that the counseling profession has been, and is, heading in the right direction. We have a long way to go, but it is nice to be on the right track.

\section{REFERENCES}

Adams, D. In, Analysis of a life satisfaction index. Journal of Gerontology, $1969,24,470-474$. 
Anastasi, A. Psychological Testing (4th ed.). New York: MacMillan, 1976.

Blake, R., counseling in gerontology. Fersonnel and Guidance Journal, $1975,53,733-737$.

Buckley, M. Counseling the aged. Personnel and Guidance Journal, $1972,50,755-758$.

Butler, R. N., \& Lewis, M. I. Aging and mental health: Positive psychosocial approaches. St. Louis: C. V. Mosby Co., 1977.

Califano, J. A.; Martinez, A.; Flemming, A. S.; Smith, D. D.; \& Hill, I. Some future prospects for the elderly population: Statistical reports on older Americans, Number 3 . Washington, D.C.: U. S. Department of Health, Education, \& Welfare, Administration on Aging; 1978.

Dickstein, L. S. Death concern: Measurement and correlates. Psychological Reports, 1972, 30, 563-571.

Florida, State of, Department of Health and Rehabilitative Services, Division of Aging needs assessment survey. Unpublished manuscript, 1975 .

Gordon, L. V. Survey of interpersonal values: Revised manual. Chicago: Science Research Associates, 1976.

Gordon, L. V. Surveg of personal values: Revised manual. Chicago: Science Research Associates, 1967.

Guertin, W. H., \& Bailey, J. P., Ir. Introduction to modern factor analysis. Ann Arbor, Mich.: Edwaras Brothers, 1970.

Harris, L. Associates. The myth and reality of aging in America. Washington, D.C.: National Council on Aging, 1975.

Myers, J. E. The development of a scale to assess counseling needs of older persons. Doctoral dissertation, University of Florida, 1978.

Nie, N. H.; Hull, C. W.; Jenkins, J. G.; Steinbrenner, K.; \& Brent, D. H. Statistical package for the social studies. New York: McGraw-Hill, 1975.

Osterbind, C. (Ed.). Population studies: 1974 age and race components of Florida's population. Gainesville: University of Elorida, 1976. 
Sinick, D. Counseling older persons: Career change and retirement. Vocational and Guidance Quarterly, 1976, 25, 18-25.

Stevens, C. N. Counseling the aged in a public housing project. personnel and Guidance Journal, 1973, 52, 189-193.

Zuckerman, M., \& Lubin, B. Multiple affect adjective checklist manual. San Diego, Calif.: Educational and Industrial Testing Service, 1965. 